\title{
Evaluation of a TrkB agonist on spatial and motor learning in the Ube3a mouse model of Angelman syndrome
}

\author{
Maria N. Schultz and Jacqueline N. Crawley \\ MIND Institute, Department of Psychiatry and Behavioral Sciences, University of California Davis School of Medicine, \\ Sacramento, California 95821, USA
}

\begin{abstract}
Angelman syndrome is a rare neurodevelopmental disorder caused by a mutation in the maternal allele of the gene Ube3a. The primary symptoms of Angelman syndrome are severe cognitive deficits, impaired motor functions, and speech disabilities. Analogous phenotypes have been detected in young adult Ube3a mice. Here, we investigate cognitive phenotypes of Ubeza mice as compared to wild-type littermate controls at an older adult age. Water maze spatial learning, swim speed, and rotarod motor coordination and balance were impaired at $6 \mathrm{mo}$ of age, as predicted. Based on previous findings of reduced brain-derived neurotrophic factor in Ube3a mice, a novel therapeutic target, the TrkB agonist 7,8-DHF, was interrogated. Semichronic daily treatment with 7,8-DHF, $5 \mathrm{mg} / \mathrm{kg}$ i.p., did not significantly improve the impairments in performance during the acquisition of the water maze hidden platform location in Ube3a mice, after training with either massed or spaced trials, and had no effect on the swim speed and rotarod deficits. Robust behavioral phenotypes in middle-aged Ube3a mice appear to result from continued motor decline. Our results suggest that motor deficits could offer useful outcome measures for preclinical testing of many pharmacological targets, with the goal of reducing symptoms in adults with Angelman syndrome.
\end{abstract}

[Supplemental material is available for this article.]

Angelman syndrome is a rare genetic neurodevelopmental disorder with a prevalence of approximately 1:15,000 births (Wheeler et al. 2017). Symptoms include severe intellectual disabilities, impaired speech, developmental delays, microcephaly, seizures, anxiety, motor dysfunctions, ataxic gait, social communication deficits, and a happy demeanor with excessive laughter (Angelman 1965; Williams et al. 2010; Bird 2014; Wheeler et al. 2017; den Bakker et al. 2018; www.angelman.org). The genetic cause of Angelman syndrome resides in a deletion at chromosomal locus 15q11-q13 (Khatri and Man 2019). Imprinted loss of the gene UBE3A within the locus, leading to reduced expression of the UBE3A ubiquitin ligase protein, is central to the disorder. Maternal transmission of the deletion results in Angelman syndrome. Paternal transmission of the deletion results in another distinct neurodevelopmental disorder, Prader-Willi syndrome (Knoll et al. 1989; Nicholls 1993; Buiting et al. 2016). Currently, no medical treatments have been approved for treating the biological causes of Angelman syndrome.

Mouse models have been generated which incorporate the loss of maternal Ube $3 a$ and display behavioral features relevant to the symptoms of Angelman syndrome, including cognitive and motor deficits (Jiang et al. 1999, 2010; Heck et al. 2008; Mabb et al. 2011; Baudry et al. 2012; Jana 2012; Kaphzan et al. 2012; Huang et al. 2013; Santini et al. 2015; Leach and Crawley 2018; Sonzogni et al. 2018). Ube3a mutant mouse models provide preclinical research tools which are advancing therapeutic discovery (van Woerden et al. 2007; Huang et al. 2011; Egawa et al. 2012; Margolis et al. 2015; Beaudet and Meng 2016; Bi et al. 2016; Tan

Corresponding author: crawley@ucdavis.edu

Article is online at http://www.learnmem.org/cgi/doi/10.1101//m.051201.119. Freely available online through the Learning \& Memory Open Access option. and Bird 2016; Ciarlone et al. 2017; Stoppel and Anderson 2017; Guzzetti et al. 2018; Lee et al. 2018; Rotaru et al. 2018; Liu et al. 2019; Rayi et al. 2019; Zylka 2020).

Angelman syndrome is a lifetime disorder. Symptoms persist across the adult lifespan (Smith 2001; Larson et al. 2015; Prasad et al. 2018). In contrast, most behavioral characterizations of Ube3a mutant mouse phenotypes have used young mice, in the 8-14 wk old range, paralleling the early stages of this neurodevelopmental disorder. Deficits have been consistently reported at younger ages on motor assays including rotarod (Miura et al. 2002; Heck et al. 2008; Jiang et al. 2010; Daily et al. 2011; Egawa et al. 2012; Huang et al. 2013; Ciarlone et al. 2017; Leach and Crawley 2018; Sonzogni et al. 2018) and open field exploratory locomotion (Allensworth et al. 2011; Huang et al. 2013; Ciarlone et al. 2017; Sonzogni et al. 2018). Additional phenotypes reported for $U b e 3 a$ mice at younger ages include anxiety-related behaviors (Jiang et al. 2010; Ciarlone et al. 2017), impaired water maze spatial learning (Miura et al. 2002; Jiang et al. 2010; Huang et al. 2013; Leach and Crawley 2018) with slower swim speeds in some genetic backgrounds (Huang et al. 2013; Leach and Crawley 2018), and impaired fear-conditioned learning and memory (Miura et al. 2002; Jiang et al. 2010; Huang et al. 2013). To our knowledge, there is only one report describing behaviors in older ages of Ube3a mice (Huang et al. 2013). Here, we focus on 6-mo-old Ube3a mice and their wild-type (WT) controls.

Several pharmacological interventions have been reported to reverse Angelman-relevant phenotypes, using young Ube3a mice 
at 6-14 wks of age. Effective treatments included the ErbB inhibitor PD158780 (Kaphzan et al. 2012), ampakine CX929 (Baudry et al. 2012), serotonin transporter inhibitor fluoxetine (Godavarthi et al. 2014), GABA-A receptor modulator ganaxolone (Ciarlone et al. 2017), HDAC inhibitor sodium valproate (Jamal et al. 2017), mTOR inhibitor rapamycin (Sun et al. 2015), mTORC2 activation (Sun et al. 2016), mitochondrial CoQ10 antioxidant (Llewellyn et al. 2015), ketone ester dietary supplementation (Ciarlone et al. 2016), and the inhibitory amino acid taurine (Guzzetti et al. 2018). Preclinically effective genetic manipulations have been reported, including the introduction of a mutation at the inhibitory phosphorylation site of alphaCaMKII (van Woerden et al. 2007), reducing Arc expression (Mandel-Brehm et al. 2015), Cre-dependent induction of the maternal Ube3a allele (Silva-Santos et al. 2015), and a zinc finger artificial transcription factor which increased Ube3a expression (Bailus et al. 2016). Importantly, more direct genetic rescues have been discovered which unsilence the normal paternal Ube3a allele, including topoisomerase I inhibitors (Huang et al. 2011; Powell et al. 2013; Mabb et al. 2016; Lee et al. 2018), microRNA miRNA-708 (Vatsa et al. 2019), and the antisense ortholog Ube3a-ATS (Meng et al. 2012, 2015).

We posed a novel therapeutic hypothesis, based on the findings of abnormal synaptic dendritic spine morphology, decreased dendritic spine density, and reduced long-term potentiation (LTP)-induced actin polymerization within dendritic spines in Ube3a mutant mice (Dindot et al. 2008; Baudry et al. 2012; Kim et al. 2016; Sun et al. 2016; Khatri et al. 2018), consistent with the role of the ubiquitin pathway in synapse formation and dendritic spine architecture (Mabb and Ehlers 2010; Williams and Franco 2010; Lee et al. 2013; Park and Poo 2013; Kim et al. 2016). Brain-derived neurotrophic factor (BDNF) is a well-established regulator of synaptic plasticity and dendritic spine formation and maintenance (Thoenen 1995; Schuman 1999; Chao 2000; Lynch et al. 2008; Monteggia 2011; Leal et al. 2015; Park and Poo 2013). BDNF exerts its synaptic actions on promoting LTP through the TrkB receptor (Reichardt 2006; Kron et al. 2014; Lin et al. 2018). TrkB agonists, including 7,8-dihydroxyflavone (7,8-DHF) and LM22A-4, were reported to improve phenotypes in mouse models of neurodegenerative and neurodevelopmental disorders, including Alzheimer's, autism spectrum disorder, Fragile X, Huntington's, and Rett syndromes (Johnson et al. 1985; Devi and Ohno 2012; Jiang et al. 2013; Simmons et al. 2013; Castello et al. 2014; Tian et al. 2015; Aytan et al. 2018; García-Díaz Barriga et al.
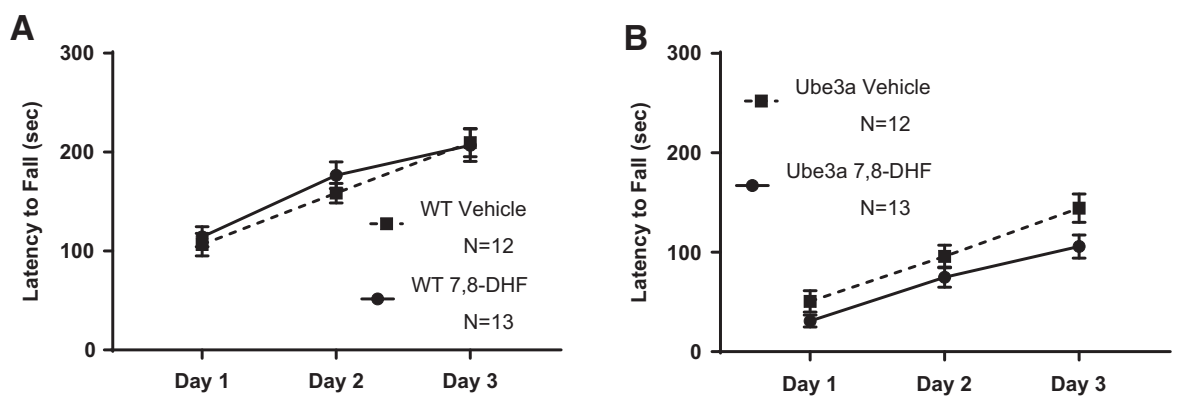

Figure 1. Rotarod motor coordination and balance performance in 6-mo-old WT and Ube3a mice given three consecutive daily training trials for $3 \mathrm{~d}$, and treated with either vehicle or the TrkB receptor agonist 7,8-dihydroxyflavanone (7,8-DHF, $5 \mathrm{mg} / \mathrm{kg}$ i.p.), showed no improvement with treatment. Consistent with previous reports for Ube3a mice at younger ages, middle-aged Ube3a mice displayed initial and continuing deficits on rotarod performance as compared to WT (for all figures, please see Results text for full statistical analyses). (A) WT in both the vehicle and 7,8-DHF groups improved across training days, displaying increasingly longer latencies to fall across training days 1,2 , and 3 , indicating normal motor learning. No significant difference was detected between WT treated with vehicle versus 7,8-DHF. (B) Ube3a in both the vehicle and 7,8-DHF treatment groups improved across training days, although latencies to fall remained lower than in WT, as expected. No significant difference was detected in performance between Ube3a mice treated with vehicle versus 7,8-DHF.
2017; Li et al. 2017; Nguyen et al. 2019; Rhine et al. 2019). Importantly, BDNF and TrkB signaling were reported to be defective Ube3a mice (Cao et al. 2013), and treatment with an ampakine which enhances BDNF effectively reversed deficits in LTP and in contextual and cued fear conditioning in 9- to 12-wk-old Ube3a mice (Baudry et al. 2012). Here, we investigate the therapeutic potential of a TrkB agonist as a pharmacological target for Angelman syndrome in older adult Ube $3 a$ mice, at age $6 \mathrm{mo}$, using Morris water maze spatial learning, a cognitive assay in which Ube3a mice have consistently displayed robust performance deficits (Miura et al. ministered before and during standard water maze training, using consecutive trials each day. In a separate group of 6-mo-old WT and Ube3a mice, 7,8-DHF was administered before and during a distributed training procedure, in which the four daily training tria separated by $1 \mathrm{~h}$ intervals. Our previous study using this spaced learning protocol discovered improved acquisition in 7- to (training with massed trials 7,-DHF treatment was designed to address the hypothesis ical intervention could produce additive or synergistic benefits in Ube $3 a$ mice at older ages.

\section{Results}

Figure 1 illustrates rotarod motor impairments in 6-mo-old Ube3a three consecutive training trials per day were administered on cant overlo $(F(2,4)=233 ., P<0$. performance in 6-mo-old Ube3a mice. Longer latencies in Ube3a than WT appeared in the first training trial, indicating a phenotypic motor deficit rather than impaired motor learning. (A) WT in days, displaying longer latencies to fall across days 1,2 , and 3 $\left(F_{(2,46)}=97.07, P<0.001\right)$. No significant difference was detected 作 . in both the vehicle and 7,8-DHF treatment groups improved across training days $\left(F_{(2,46)}=87.31, P<0.001\right)$, although latencies to fall were shorter than in WT, as predicted. No significant difference was detected across training days between $U b e 3 a$ treated with vehicle versus $U b e 3 a$ treated with 7,8 -DHF $\left(F_{(2,46)}=1.371\right.$, NS). Interaction of training day $\times$ treatment was not significant $\left(F_{(1,23)}=3.838, P=0.0623\right.$, NS). Note that only the first cohort of mice was used in rotarod testing, based on previous findings that rotarod performance did not differ between massed and spaced training conditions in either WT or Ube3a mice (Lauterborn et al. 2019).

Figure 2 illustrates Morris water maze spatial learning impairments in 6-mo-old Ube3a mice as compared to WT, when trained with the conventional four massed daily training trials. The performance was unaffected by semi-chronic treatment with daily intraperitoneal doses of the TrkB receptor agonist 7,8-dihydroxyflavanone (7,8-DHF, $5 \mathrm{mg} / \mathrm{kg}$ ). (A) WT in both the vehicle and 7,8-DHF 

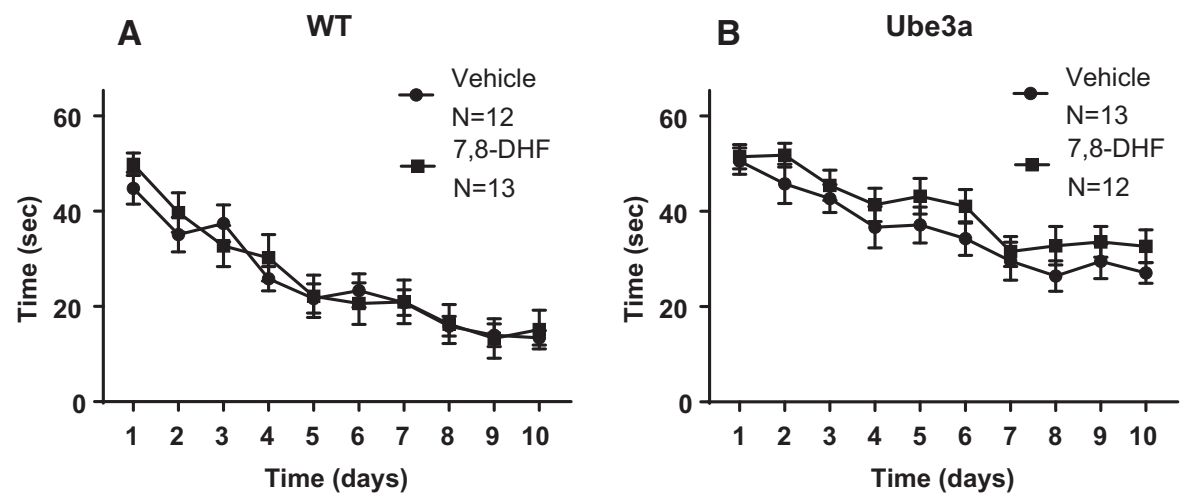

Figure 2. Morris water maze spatial learning and memory in WT and Ube3a mice given four consecutive daily training trials and treated with either vehicle or with the TrkB receptor agonist 7,8-dihydroxyflavanone (7,8-DHF, $5 \mathrm{mg} / \mathrm{kg}$ i.p.). (A) WT in both the vehicle and 7,8-DHF groups successfully reached the acquisition criterion of under $15 \mathrm{sec}$ to reach the hidden platform location. No significant difference was detected in the time course for acquisition across training days between WT mice treated with vehicle versus 7,8-DHF. (B) Ube3a in both the vehicle and 7,8-DHF groups did not successfully reach the acquisition criterion of under $15 \mathrm{sec}$ to reach the hidden platform location, although improvement across training days was apparent in both groups. No significant difference was detected in the time course across training days for acquisition between Ube3a mice treated with vehicle versus 7,8-DHF.

groups successfully reached the acquisition criterion of $\leq 15 \mathrm{sec}$ to reach the hidden platform location. A significant effect of the training day was detected in WT $\left(F_{(9,207)}=32.49, P<0.001\right)$, indicating learning across days as expected. No significant difference was detected in the time course for acquisition across training days between WT treated with vehicle versus WT treated with 7,8-DHF $\left(F_{(1,23)}=0.06\right.$, NS), indicating no faster learning in WT given 7,8-DHF. No significant interaction between vehicle versus $7,8-\mathrm{DHF} \times$ training day was detected in WT $\left(F_{(9,207)}=0.67, \mathrm{NS}\right)$. (B) Ube $3 a$ in both the vehicle and 7,8-DHF groups did not reach the acquisition criterion of $\leq 15 \mathrm{sec}$ to reach the hidden platform location. A significant effect of the training day was detected $\left(F_{(9,207)}=13.75\right.$, $P<0.001$ ), indicating some learning across training days. No significant difference was detected in the time course across training days for acquisition by Ube3a mice treated with vehicle versus 7,8 -DHF $\left(F_{(1,23)}=2.89, \mathrm{NS}\right)$, indicating no faster learning with 7,8-DHF. No significant interaction between vehicle versus 7,8 -DHF $\times$ training day was detected in Ube $3 a\left(F_{(9,207)}=0.225\right.$, NS $)$.

Figure 3 illustrates that Morris water maze spatial learning was impaired in 6-mo-old Ube3a mice when trained with spaced trials, that is, four daily training trials spaced at $1 \mathrm{~h}$ intervals, but unaffected by treatment with daily intraperitoneal doses of the TrkB receptor agonist 7,8-dihydroxyflavanone (7,8-DHF, $5 \mathrm{mg} /$ $\mathrm{kg}$ ) as compared to vehicle, on latencies to reach the hidden platform. (A) WT in both the vehicle and 7,8-DHF groups successfully reached the acquisition criterion of $\leq 15 \mathrm{sec}$ to reach the hidden platform location. A significant effect of the training day was detected in WT $\left(F_{(9,108)}=\right.$ 9.8, $P<0.001)$, indicating learning across days as expected. No significant difference was detected in the time course for acquisition across training days between
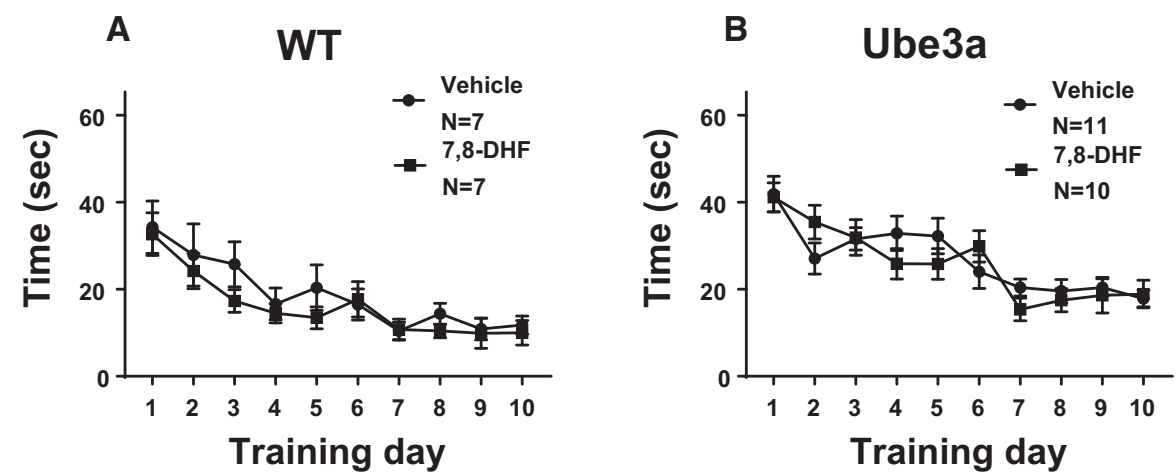

Figure 3. Latencies to reach the hidden platform during Morris water maze spatial learning and memory in WT and Ube3a mice given four daily training trials spaced at $1 \mathrm{~h}$ intervals, and treated with either vehicle or the TrkB receptor agonist 7,8-dihydroxyflavanone (7,8-DHF, $5 \mathrm{mg} / \mathrm{kg}$ i.p.). (A) WT in both the vehicle and 7,8-DHF groups successfully reached the acquisition criterion of under 15 sec to reach the hidden platform location. No significant difference was detected in the time course for acquisition across training days in WT mice treated with vehicle and 7,8-DHF. (B) Ube3a in both the vehicle and 7,8-DHF groups did not successfully reach the acquisition criterion of under 15 sec to reach the hidden platform location, although acquisition latencies at day 10 were generally lower after spaced training trials than latencies at day 10 after the massed training trials shown in Figure 2. This observation extends previous findings of better learning with spaced versus massed training in 2to 3-mo-old Ube3a mice (Lauterborn et al. 2019). No significant difference was detected in the time course across training days for acquisition by Ube3a mice treated with vehicle versus 7,8-DHF. 
A
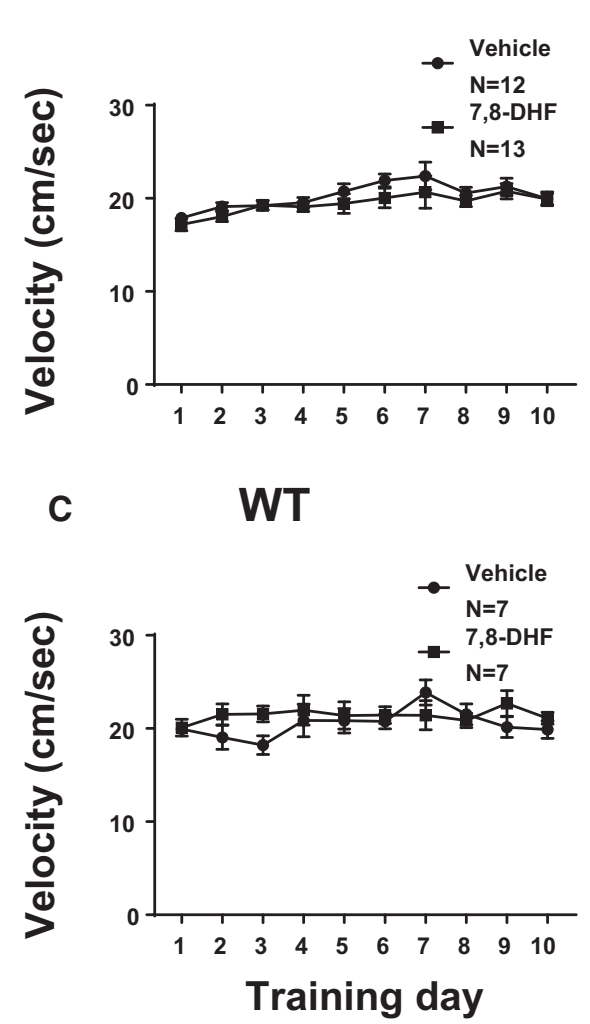

B Ube3a

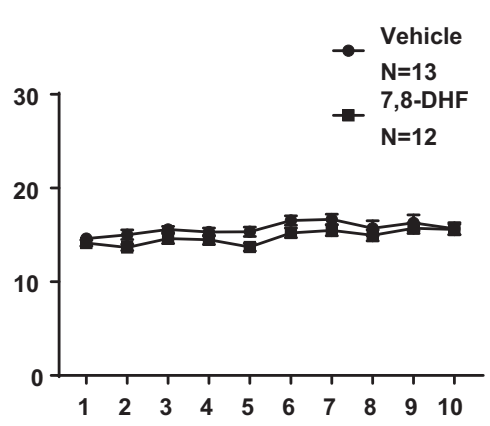

D Ube3a

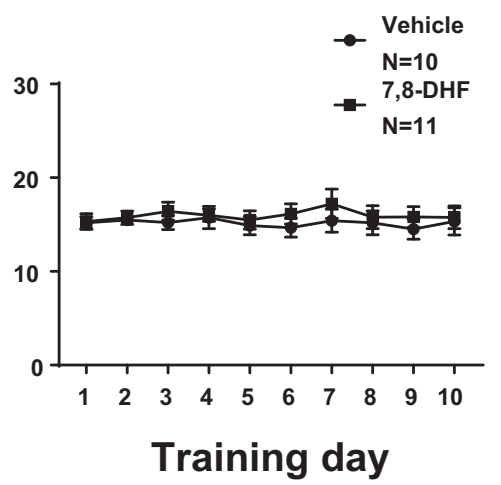

Figure 4. Speed of swimming during Morris water maze spatial learning in WT and Ube3a mice given four consecutive daily training trials $(A, B)$, or four daily training trials spaced by $1 \mathrm{~h}$ intervals $(C, D)$, and treated with either vehicle or the TrkB receptor agonist 7,8-dihydroxyflavanone (7,8-DHF, $5 \mathrm{mg} / \mathrm{kg}$ i.p.). Ube3a swam more slowly than WT overall in both training conditions $(P<0.001)$. (A) The velocity of swimming did not differ between WT mice treated with vehicle versus 7,8-DHF. A significant effect of the training day was detected in WT $(P<0.001)$, indicating slightly faster swimming during the latter training days. No significant interaction between vehicle versus $7,8-\mathrm{DHF} \times$ training day was detected in WT. (B) The velocity of swimming did not differ between Ube3a mice treated with vehicle versus 7,8-DHF. A significant effect of the training day was detected $(P<0.001)$, indicating somewhat faster swimming across training days. No significant interaction between vehicle versus $7,8-\mathrm{DHF} \times$ training day was detected in Ube3a. (C) The velocity of swimming did not differ between WT mice given spaced training trials and treated with vehicle versus 7,8-DHF. No effect of the training day was detected in WT. A significant interaction between vehicle versus $7,8-\mathrm{DHF} \times$ training day was detected in WT $(P<$ $0.001)$. (D) The velocity of swimming did not differ between Ube $3 a$ mice given spaced training trials and treated with vehicle versus 7,8-DHF. No significant effect of the training day was detected in Ube $3 a$. No significant interaction between vehicle versus 7,8-DHF $\times$ training day was detected in Ube3a.

However, swim speed was significantly lower in Ube $3 a$ overall as compared to WT overall $\left(F_{(1,39)}=25.5, P<0.001\right)$. A parsimonious explanation for the apparent acquisition deficit, in which Ube3a displayed longer latencies to reach the hidden platform, is, therefore, slower swimming. Because swim speeds were somewhat lower in Ube $3 a$ than WT in both the massed and spaced training groups, slower latencies to reach the hidden platform could be responsible for the apparent learning deficits. Results from these experiments may be more correctly interpreted as a performance deficit in Ube3a, rather than a cognitive deficit. 7,8-DHF treatment had no effect on the performance deficit.

Probe trial performance at $3 \mathrm{~h}$ after the last training trial indicated that 6-mo-old Ube $3 a$ mice used distal spatial cues to achieve their moderate level of learning of the water maze platform locations, with no improvement in probe trial scores by 7,8-DHF treatment, as shown in Supplemental Figure S1. Both WT and Ube3a trained with four massed daily trials displayed significantly more time spent in the previously trained quadrant than in the other four quadrants, independent of treatment group (WT + vehicle $F_{(3,48)}=7.79$, $P<0.001 ; \quad$ WT $+7,8$-DHF $\quad F_{(3,44)}=9.018$, $P<0.001 ;$ Ube $3 a+$ vehicle $F_{(3,48)}=4.044$, $P<0.05 ; \quad U b e 3 a+7,8$-DHF $F_{(3,44)}=3.66$, $P<0.05)$. Similarly, crossings over the previously trained platform location were higher than crossings over the other three analogous imaginary platform locations for both WT and Ube3a trained with four massed daily training trials $(\mathrm{WT}+\mathrm{ve}-$ hicle $F_{(3,44)}=14.91, \quad P<0.001 ; \quad$ WT + 7,8-DHF $F_{(3,48)}=15.32, P<0.001 ;$ Ube $3 a+$ vehicle $\left(F_{(3,48)}=8.026, P<0.001 ; U b e 3 a+\right.$ 7,8 -DHF $\left.F_{(3,46)}=9.851, P<0.001\right)$.

Analogous $3 \mathrm{~h}$ probe trial results were obtained for the 6-mo-old WT and Ube3a mice trained with four daily training trials that were spaced at $1 \mathrm{~h}$ intervals, as shown in Supplemental Figure S2 (Quadrant time: WT + vehicle $F_{(3,42)}=9.026, P<0.001 ; \mathrm{WT}$ $+7,8$-DHF $F_{(3,44)}=7.29, P<0.001 ;$ Ube $3 a+$ vehicle $F_{(3,40)}=9.432, P<0.001 ; U b e 3 a+$ 7,8-DHF $F_{(3,36)}=0.348$, NS; Platform crossings: $\mathrm{WT}+$ vehicle $F_{(3,24)}=28.83, P<0.001$; WT + 7,8-DHF $\quad F_{(3,24)}=24.54, \quad P<0.001$; Ube $3 a+$ vehicle $F_{(3,40)}=31.66, \quad P<0.001$; Ube $3 a+7,8$-DHF), indicating that some spatial learning based on distal environmental cues had occurred in the Ube $3 a$ mice.

Probe trial performance at $24 \mathrm{~h}$ after the last training trial indicated that 6-moold Ube $3 a$ mice retained partial memory of the water maze platform locations in some cases, following their impaired performance on acquisition, although 7,8-DHF treatment did not improve probe trial scores. WT trained with either four massed training trials (Supplemental Fig. S3) or four spaced training trials (Supplemental Fig. S4) displayed selective quadrant search and more crossings over the previously trained quadrant location at the $24 \mathrm{~h}$ time point, in both the vehicle and 7,8-DHF treatment groups (Massed quadrant time: WT + vehicle $F_{(3,44)}=$ 7.253, $P<0.001 ; \mathrm{WT}+7,8$-DHF $F_{(3,48)}=$ 5.797, $P<0.01$; Massed platform crossings: WT + vehicle $F_{(3,44)}=$ 9.58, $P<0.001$; WT $+7,8$-DHF $F_{(3,48)}=7.4, P<0.001$; Spaced quadrant time: $\mathrm{WT}+$ vehicle $F_{(3,24)}=4.212, \quad P<0.05 ; \mathrm{WT}+7,8-\mathrm{DHF}$ $F_{(3,24)}=3.313, P<0.05$; Spaced platform crossings: WT + vehicle $\left.F_{(3,24)}=19.96, P<0.001 ; \mathrm{WT}+7,8-\mathrm{DHF} F_{(3,24)}=9.137, P<0.001\right)$. Ube $3 a$ trained with either four massed or four spaced training trials displayed selective quadrant search and more crossings over the previously trained quadrant location in the $24 \mathrm{~h}$ probe trial on some, but not all, parameters (Massed quadrant time: Ube $3 a+$ vehicle $F_{(3,48)}=5.797, \quad P<0.01 ; \quad U b e 3 a+7,8$-DHF $F_{(3,44)}=1.25$, NS; Massed platform crossings: Ube $3 a+$ vehicle $F_{(3,48)}=10.16, \quad P<$ 0.001 ; Ube $3 a+7,8$-DHF $F_{(3,44)}=4.95, P<0.01$; Spaced quadrant time: Ube $3 a+$ vehicle $F_{(3,40)}=7.416, P<0.001 ; U b e 3 a+7,8$-DHF $F_{(3,36)}=2.015$, NS; Spaced platform crossings: Ube $3 a+$ vehicle $F_{(3,24)}=9.137, P<0.001 ;$ Ube $3 a+7,8$-DHF $F_{(3,36)}=2.861, P=0.052$, NS). Further investigation will be required to understand the observed impairments in groups treated with 7,8-DHF on $24 \mathrm{~h}$ probe trial performance on some parameters. In addition, the observation 
from probe trial results that the spatial location of the hidden platform was acquired by the Ube $3 a$ groups to some extent will be interesting to investigate further.

\section{Discussion}

Adults with Angelman syndrome continue to display most of the symptoms characterized at younger ages, including impaired locomotion and mobility, continuing severe cognitive impairments, limited speech, anxiety, sleep dysfunction, seizures, obesity, and gastrointestinal disruption (Smith 2001; Larson et al. 2015; Prasad et al. 2018). The present studies used older adult male and female Ube3a mutant mice to model spatial and motor learning deficits relevant to cognitive deficits in Angelman syndrome, and to evaluate a hypothesis-driven pharmacological intervention.

Extending previous reports of motor behavioral phenotypes in younger Ube3a mice, (Miura et al. 2002; Heck et al. 2008; Jiang et al. 2010; Daily et al. 2011; Egawa et al. 2012; Huang et al. 2013; Ciarlone et al. 2017; Leach and Crawley 2018; Sonzogni et al. 2018), rotarod motor coordination and balance was significantly impaired in 6-mo-old $U b e 3 a$ as compared to WT in the present study. Swim speeds were lower in Ube $3 a$ as compared to WT at age $6 \mathrm{mo}$, as discussed below. Similarly, lower open field locomotor activity has been extensively documented in Ube3a mice at younger ages (Allensworth et al. 2011; Huang et al. 2013; Ciarlone et al. 2017; Sonzogni et al. 2018), and in our recent report of Ube3a mice at 12 mo of age (Dutta and Crawley 2019). Further, number of total arm entries into the elevated plus-maze, the internal measure of general exploratory locomotion, and number of entries into the side chambers of the 3-chambered social approach apparatus, was significantly lower in 12-mo-old Ube3a mice as compared to WT controls, consistent with the open field results (Dutta and Crawley 2019).

Intellectual impairment is a primary symptom of Angelman syndrome. Therapeutics that improve cognitive abilities could provide an important benefit to adults with Angelman syndrome. Previous studies reported reduced BDNF and TrkB signaling in Ube $3 a$ mice (Cao et al. 2013), and that treatment with an ampakine which elevates BDNF was effective in reversing a deficit in contextual and cued fear conditioning in young Ube3a mice (Baudry et al. 2012). Following our previous confirmation of deficits in water maze performance in young Ube3a mice (Leach and Crawley 2018), older adult Ube3a and WT mice were used in the present studies to evaluate water maze performance and the effects of semichronic treatment with the TrkB agonist 7,8-DHF. Based on our previous findings of compromised motor functions in 12-mo-old Ube3a mice (Dutta and Crawley 2019), which could introduce direct artifacts into many cognitive assays for mice, we focused on the 6 mo age for the evaluation of a novel pharmacological strategy in learning tasks in the present studies. Apparent acquisition deficits in water maze spatial learning were again detected in vehicletreated Ube $3 a$ mice at this age. Specifically, WT reached the acquisition criterion of $15 \mathrm{sec}$ latency to reach the hidden platform by 10 $\mathrm{d}$ of training, whereas Ube $3 a$ did not reach the acquisition criterion, averaging $\sim 30-35 \mathrm{sec}$ to reach the hidden platform after $10 \mathrm{~d}$ of massed training trials. At $5 \mathrm{mg} / \mathrm{kg}$ i.p., the semichronic dose used, 7,8-DHF did not improve acquisition in Ube $3 a$ mice. We then repeated this experiment in a separate cohort of 6-mo-old Ube $3 a$ and WT mice using spaced training trials. Previously we had discovered that spacing the training trials by $1 \mathrm{~h}$ intervals improved acquisition in young Ube3a mice (Lauterborn et al. 2019). To test the hypothesis that the combination of spaced training plus TrkB receptor activation could additively or synergistically improve water maze performance in Ube $3 a$ mice, the second independent cohort of 6-mo-old Ube $3 a$ and WT was trained with four daily spaced trials and $5 \mathrm{mg} / \mathrm{kg}$ 7,8-DHF. WT again reached the acquisition criterion of $15 \mathrm{sec}$ latency to reach the hidden platform by $10 \mathrm{~d}$ of training. Ube3a did not reach the acquisition criterion, but averaged $\sim 20$ sec to reach the hidden platform after $10 \mathrm{~d}$ of training, considerably better than the group trained with massed trials, replicating and extending our previous findings (Lauterborn et al. 2019). The 7,8-DHF treatment did not further improve acquisition in Ube 3 a mice.

It is important to recognize that reduced swim speeds were apparent in both groups of 6-mo-old Ube $3 a$ mice as compared to WT. In addition, probe trial performance was almost as good in $U b e 3 a$ as in WT, consistent with our previous findings in younger WT and Ube3a mice (Lauterborn et al. 2019), indicating that the location of the hidden platform was acquired to some extent in all Ube3a groups. However, given that 6-mo-old Ube3a mice displayed selective quadrant and platform location search in some of the probe trials, and based on the slower swim speeds in Ube $3 a$ than WT shown in Figure 4, results from the Ube $3 a$ water maze experiments may be most parsimoniously interpreted as motor rather than cognitive deficits.

The interpretation of partial acquisition and memory of this spatial learning task using distal environmental cues in middleaged adult Ube3a mice suggests that improvement in learning and memory may be possible in adult Ube3a mice. Learning and memory tasks that do not rely heavily on motor performance, such as fear conditioning and operant tasks, will be needed to more fully evaluate cognitive phenotypes in older Ube3a mice, which could serve as outcome measures for future therapeutic discovery.

It is interesting to note that similar but not identical results were obtained from WT and Ube $3 a$ mice purchased from JAX (Cohort 1) versus bred in-house (Cohort 2). Another difference between the two cohorts was that Cohort 1 consisted of males only, while Cohort 2 consisted of both males and females. No obvious sex differences were seen within Cohort 2, although Ns were insufficient for proper statistical comparison. It remains possible that the small differences in absolute values of water maze latencies between Cohorts 1 and 2 could be related to different breeding colony conditions or to a potential sex difference.

The present negative findings indicate that a TrkB agonist strategy may not be directly useful for Angelman syndrome. However, other dose regimens of 7,8-DHF and other more selective TrkB agonists remain to be tested and could yield more positive results. The $5 \mathrm{mg} / \mathrm{kg}$ i.p. dose and semi-chronic administration used in the present studies are consistent with an extensive literature in which this dose produced behavioral actions, and significantly activated TrkB receptors as assayed with Western immunoblots for levels of phosphorylated TrkB, in several brain regions in various mouse models on diverse genetic backgrounds (Andero et al. 2011; Devi and Ohno 2012; Jiang et al. 2013; Sconce et al. 2015; Tan and Bird 2016; García-Díaz Barriga et al. 2017; Stagni et al. 2017; Giacomini et al. 2019; Seese et al. 2020). Future experiments with pTrkB assays will be necessary to fully confirm target engagement in 6-mo-old Ube3a mice.

It is important to consider the possibility that treatments beginning at adult ages may reduce the likelihood of therapeutic improvements. Beginning a neurotrophic drug intervention early in life, during a critical period of brain development, may be essential for neurodevelopmental disorders such as Angelman syndrome (Sonzogni et al. 2019). Although TrkB agonists have been shown to improve components of social and motor behaviors in adult mice (Simmons et al. 2013; Kang et al. 2017; Li et al. 2017; Nasrallah et al. 2019; Rhine et al. 2019), brain disorders with structural neuroanatomical abnormalities established during early development, such as reductions in myelination which have been reported for Angelman syndrome (Harting et al. 2009; Peters 
et al. 2011; Tiwari et al. 2012; Grier et al. 2015), may require that neurotrophic interventions begin at a very young age (SilvaSantos et al. 2015; Sonzogni et al. 2019).

Reporting negative as well as positive results is especially important at the preclinical phase of evaluating therapeutics for neurodevelopmental disorders. Although negative results were obtained with the present 7,8-DHF treatment regimen, our findings support the feasibility of using older adult Ube $3 a$ mice to test a wide range of therapeutic targets. The present results, along with our recent report (Dutta and Crawley 2019), demonstrate the presence of robust motor deficits in 6- and 12-mo-old Ube3a mice. Therefore, impaired performance on parameters of rotarod motor coordination and balance, open field exploratory locomotion, number of chamber entries during the 3-chambered social approach, and swim speeds during water maze learning, could provide strong outcome measures for evaluating improvements in behavioral phenotypes of adult Ube3a mice after pharmacological interventions.

Efficacious interventions for adults with Angelman syndrome could significantly improve the quality of life. Impressively diverse strategies have been used in the preclinical evaluation of pharmacological and genetic interventions, using prenatal, juvenile and young adult ages of $U b e 3 a$ mice, as appropriate for the discovery of cures early in life (van Woerden et al. 2007; Huang et al. 2011; Baudry et al. 2012; Kaphzan et al. 2012; Meng et al. 2012, 2015; Powell et al. 2013; Godavarthi et al. 2014; Llewellyn et al. 2015; Mandel-Brehm et al. 2015; Silva-Santos et al. 2015; Sun et al. 2015, 2016; Bailus et al. 2016; Ciarlone et al. 2016, 2017; Mabb et al. 2016; Jamal et al. 2017; Guzzetti et al. 2018; Lee et al. 2018; Zylka 2020). Our results indicate that behavioral phenotypes in Ube $3 a$ mice are similarly robust at older adult ages. In particular, motor deficits in older Ube $3 a$ mice may provide optimal preclinical opportunities to identify pharmacological interventions which may significantly improve components of the symptomatology which persist in adults with Angelman syndrome.

\section{Materials and Methods}

\section{Mice}

Conventional Ube $3 a$ knockout mice, derived from maternal transmission and generated on a C57BL/6J background, were purchased from The Jackson Laboratory (JAX) in Bar Harbor, Maine (JAX catalog \#016590), along with their WT littermates (Cohort 1, males). Breeding pairs of female Ube $3 a$ and male WT were subsequently purchased from JAX, and breeding of Cohort 2 was conducted at the University of California Davis in Sacramento, CA, USA. Female Ube $3 a$ were bred with male WT to maintain maternal transmission of the heterozygous mutation. Offspring were housed in cages containing same-sex littermates, 2-4 mice per cage (Cohort 2 , males and females). Mice were housed in ventilated Tecniplast cages in an AAALAC approved temperature-controlled vivarium on a 12:12 circadian cycle with lights on at 7 a.m. All husbandry, breeding, behavioral testing, and drug treatment procedures were approved by the University of California Davis Institutional Animal Care and Use Committee, and were conducted in compliance with the NIH Guide for the Care and Use of Laboratory Animals.

\section{Methodological considerations}

Behavioral testing was conducted during the light phase of the circadian cycle, between 8.30 a.m. and 5.30 p.m. On the day of each behavioral experiment, mice in their home cages were habituated to the testing room for $1 \mathrm{~h}$ before the start of the assay. To evaluate phenotypes in older adult Ube $3 a$ and WT mice, behavioral assays were conducted at ages 6 mo of age. To investigate treatment effects on a task that directly addresses motor coordination and balance, rotarod motor learning was tested in Cohort 1 one week before the start of water maze testing. Cohort 1, including a total of 25 WT and 25 Ube $3 a$, males only, was tested on Morris water maze with massed training trials and drug or vehicle treatment. A separate set of female Ube3a and male WT breeders was ordered from JAX and bred in-house, to generate males and females for an initial partial evaluation of sex differences. Cohort 2, bred in-house, including a total of $14 \mathrm{WT}$ and $21 \mathrm{Ube} 3 a$, approximately equal numbers of males and females, was tested on Morris water maze spatial learning with spaced training trials. Purchases and breeding were designed to yield Ns of sufficient power to detect drug effects, as confirmed in previous studies (Silverman et al. 2011, 2012; Brielmaier et al. 2012; Kazdoba et al. 2016; Leach and Crawley 2018; Stoppel et al. 2018). Comparison of massed versus spaced training in vehicle-treated $U b e 3 a$ and WT was designed as a replication and extension study, to evaluate the beneficial effects of spaced training that we previously detected in Ube3a mice at a younger age (Lauterborn et al. 2019).

Mice were coded by ear notch pattern to ensure that investigators remained uninformed of genotype. Automated videotracking equipment was used for the water maze assay. Observers scored rotarod latencies. Investigators remained blind to treatment condition through coding of drug and vehicle vials by another investigator. Each subject mouse was weighed on the morning of each drug treatment, for calculations of dose by body weight. The 7,8-DHF dose was chosen from previous publications on behavioral actions of 7,8-DHF in mice, in which no adverse health effects were reported (Devi and Ohno 2012; Castello et al. 2014; Ren et al. 2014; Stagni et al. 2017; Rhine et al. 2019). For all assays, surfaces of the testing chamber were cleaned with $70 \%$ ethanol after each subject mouse was tested, with sufficient time for the ethanol odor to dissipate before the start of the next test session.

\section{Behavioral testing methods}

\section{Rotarod}

Rotarod motor coordination and balance was tested using an Ugo-Basile accelerating mouse rotarod, (Stoelting Co., Wood Dale, IL) as previously described (Silverman et al. 2011; Leach and Crawley 2018; Lauterborn et al. 2019). Rotations increased from 5 to $40 \mathrm{rpm}$ across the $5 \mathrm{~min}$ test session. Three trials per day were administered across three consecutive days. Latency to fall was automatically detected by the equipment and recorded for each trial.

\section{Water maze}

Morris water maze spatial learning and memory was tested using methods previously described (Brielmaier et al. 2012; Leach et al. 2016; Leach and Crawley 2018; Lauterborn et al. 2019). The 120 $\mathrm{cm}$ circular pool was filled with water maintained at $24^{\circ} \mathrm{C}-25^{\circ} \mathrm{C}$, mixed with dilute Crayola nontoxic liquid white paint for opacity, to prevent proximal visual detection of the hidden platform. Room lighting was $\sim 25$ lux. External cues for distal spatial navigation included a prominent sink, computer, water temperature regulator with hose, a large colorful poster, and a yellow paper lantern hung from the ceiling. Platform locations and start locations were pseudorandomized. Trials were videorecorded and scored by automated software (Noldus Ethovision). Hidden platform acquisition was quantified for latency to find the hidden platform and swim speed. For the conventional massed training trials experiment, each subject mouse was given four consecutive trials per day for $10 \mathrm{~d}$. The WT control group reached the criterion of 15 sec or less latency to reach the hidden platform by day 10 .

Our previous study with young Ube 3 a mice revealed improved learning when training trials were temporally spaced instead of massed (Lauterborn et al. 2019). We therefore conducted spaced training trials in a separate group of 6 mo old WT and Ube3a mice (Cohort 2). Each subject mouse was given four trials per day separated by $1 \mathrm{~h}$ between each trial, for $10 \mathrm{~d}$. The WT control group reached the latency criterion of $15 \mathrm{sec}$ or less to reach the hidden platform by day 10 . In both groups, mice were allowed to remain on the platform for $\sim 15 \mathrm{sec}$ after each trial. Each mouse was placed 
under an infrared heating lamp to help restore body temperature, at the end of the fourth daily trial in the massed training of Cohort 1 , and between trials in the spaced training of Cohort 2 .

Probe trial analysis was conducted at $3 \mathrm{~h}$ after the last training trial, to confirm that the acquisition strategy used distal spatial cues. A second probe trial was conducted at $24 \mathrm{~h}$ after the last training trial, to evaluate long-term memory of the location of the hidden platform. The duration of each probe trial was $60 \mathrm{sec}$. Time spent in each of the four quadrants of the pool, and number of crossings over the former platform location versus the three analogous imaginary platform locations in the other three quadrants, were automatically scored by the Noldus videotracking software.

\section{Drug administration}

7,8-dihydroxyflavanone (7,8-DHF, catalog \#D5446, SigmaAldrich) stock was dissolved in dimethyl sulfoxide (DMSO, Sigma-Aldrich) and diluted fresh on the day of injections with phosphate-buffered saline $(0.1 \mathrm{M}$, Thermo Fisher Scientific), to reach the treatment preparation of $0.5 \mathrm{mg} / \mathrm{mL} 7,8$-DHF in $17 \%$ DMSO. The vehicle solution was similarly prepared fresh on the day of injections and consisted of $17 \%$ DMSO in $0.1 \mathrm{M}$ phosphatebuffered saline. Intraperitoneal injection volume was $10 \mathrm{~mL} / \mathrm{kg}$, yielding a 7,8-DHF dose of $5 \mathrm{mg} / \mathrm{kg}$. Subject mice were injected with either 7,8-DHF or vehicle daily for $5 \mathrm{~d}$ before the start of treatment. Starting on day 6 and continuing through the last day of each testing sequence, each mouse was injected $1 \mathrm{~h}$ before the start of behavioral testing.

\section{Statistics}

GraphPad Prism version 7 was used to conduct statistical analyses of the data and to generate graphs. Rotarod motor learning was analyzed by two-way repeated measures ANOVA for factors of training day and treatment. Water maze acquisition and swim speed were analyzed with a two-way repeated measures ANOVA for factors of training day and treatment, followed by Bonferroni posthoc analyses in cases of significant ANOVA F-values. Overall genotype differences in rotarod performance and in swim speed were analyzed with a two-way analysis of variance. Water maze probe trial data were analyzed with one-way ANOVA followed by posthoc Dunnett's test comparing the target location to the three other locations, within genotype and within treatment condition.

\section{Acknowledgments}

We are grateful to Dr. Gary Lynch, Dr. Christine Gall, and Dr. Julie Lauterborn, University of California Irvine, for discussions of the concepts underlying these studies, in particular the TrkB agonist pharmacological strategy. We thank Prescott Leach, Tatiana Kazdoba, and Jennifer Parrott for their pilot studies and published findings, which informed our choice of the 7,8-DHF dose and treatment regimen. This work was supported by the National Institutes fof Health grants R01 NS085709 (J.N.C.) and U54 HD079125 (J.N. C.).

\section{References}

Allensworth M, Saha A, Reiter LT, Heck DH. 2011. Normal social seeking behavior, hypoactivity and reduced exploratory range in a mouse model of Angelman syndrome. BMC Genet 12: 7. doi:10.1186/1471-2156-12-7 Andero R, Heldt SA, Ye K, Liu X, Armario A, Ressler KJ. 2011. Effect of 7,8-dihydroxyflavone, a small-molecule TrkB agonist, on emotional learning. Am J Psychiatry 168: 163-172. doi:10.1176/appi.ajp.2010 .10030326

Angelman H. 1965. 'Puppet' children: a report of three cases. Dev Med Child Neurol 7: 681-688. doi:10.1111/j.1469-8749.1965.tb07844.x

Aytan N, Choi J-K, Carreras I, Crabtree L, Nguyen B, Lehar M, Blusztajn JK, Jenkins BG, Dedeoglu A. 2018. Protective effects of

7,8-dihydroxyflavone on neuropathological and neurochemical changes in a mouse model of Alzheimer's disease. Eur J Pharmacol 828: 9-17. doi:10.1016/j.ejphar.2018.02.045

Bailus BJ, Pyles B, McAlister MM, O'Geen H, Lockwood SH, Adams AN, Nguyen JT, Yu A, Berman RF, Segal DJ. 2016. Protein delivery of an artificial transcription factor restores widespread Ube3a expression in an
Angelman syndrome mouse brain. Mol Ther 24: 548-555. doi:10.1038/ mt.2015.236

Baudry M, Kramar E, Xu X, Zadran H, Moreno S, Lynch G, Gall C, Bi X. 2012. Ampakines promote spine actin polymerization, long-term potentiation, and learning in a mouse model of Angelman syndrome. Neurobiol Dis 47: 210-215. doi:10.1016/j.nbd.2012.04.002

Beaudet AL, Meng L. 2016. Gene-targeting pharmaceuticals for single-gene disorders. Hum Mol Genet 25: R18-R26. doi:10.1093/hmg/ddv476

Bi X, Sun J, Ji AX, Baudry M. 2016. Potential therapeutic approaches for Angelman syndrome. Expert Opin Ther Targets 20: 601-613. doi:10 $1517 / 14728222.2016 .1115837$

Bird LM. 2014. Angelman syndrome: review of clinical and molecular aspects. Appl Clin Genet 7: 93-104. doi:10.2147/TACG.S57386

Brielmaier J, Matteson PG, Silverman JL, Senerth JM, Sm K, Genestine M, Millonig JH, DiCicco-Bloom E, Crawley JN. 2012. Autism-relevant social abnormalities and cognitive deficits in Engrailed-2 knockout mice. PLoS One 7: e40914. doi:10.1371/journal.pone.0040914

Buiting K, Williams C, Horsthemke B. 2016. Angelman syndrome-insights into a rare neurogenetic disorder. Nat Rev Neurol 12: 584-593. doi:10 $.1038 /$ nrneurol.2016.133

Cao C, Rioult-Pedotti MS, Migani P, Yu CJ, Tiwari R, Parang K, Spaller MR, Goebel DJ, Marshall J. 2013. Impairment of TrkB-PSD-95 signaling in Angelman syndrome. PLoS Biol 11: e1001478. doi:10.1371/journal.pbio .1001478

Castello NA, Nguyen MH, Tran JD, Cheng D, Green KN, LaFerla FM. 2014. 7,8-Dihydroxyflavone, a small molecule TrkB agonist, improves spatial memory and increases thin spine density in a mouse model of Alzheimer disease-like neuronal loss. PLoS One 9: e91453. doi:10.1371/journal .pone.0091453

Chao MV. 2000. Trophic factors: an evolutionary cul-de-sac or door into higher neuronal function? J Neurosci Res 59: 353-355. doi:10.1002/ (SICI)1097-4547(20000201)59:3<353::AID-JNR8>3.0.CO;2-S

Ciarlone SL, Grieco JC, D'Agostino DP, Weeber EJ. 2016. Ketone ester supplementation attenuates seizure activity, and improves behavior and hippocampal synaptic plasticity in an Angelman syndrome mouse model. Neurobiol Dis 96: 38-46. doi:10.1016/j.nbd.2016.08.002

Ciarlone SL, Wang X, Rogawski MA, Weeber EJ. 2017. Effects of the synthetic neurosteroid ganaxolone on seizure activity and behavioral deficits in an Angelman syndrome mouse model. Neuropharmacology 116: $142-150$. doi:10.1016/j.neuropharm.2016.12.009

Daily JL, Nash K, Jinwal U, Golde T, Rogers J, Peters MM, Burdine RD, Dickey C, Banko JL, Weeber EJ. 2011. Adeno-associated virus-mediated rescue of the cognitive defects in a mouse model for Angelman syndrome. PLoS ONE 6: e27221. doi:10.1371/journal.pone.0027221

den Bakker H, Sidorov MS, Fan Z, Lee DJ, Bird LM, Chu CJ, Philpot BD. 2018. Abnormal coherence and sleep composition in children with Angelman syndrome: a retrospective EEG study. Mol Autism 9: 32. doi:10.1186/ s13229-018-0214-8

Devi L, Ohno M. 2012. 7,8-dihydroxyflavone, a small-molecule TrkB agonist, reverses memory deficits and BACE1 elevation in a mouse model of Alzheimer's disease. Neuropsychopharmacology 37: 434-444. doi:10.1038/npp.2011.191

Dindot SV, Antalffy BA, Bhattacharjee MB, Beaudet AL. 2008. The Angelman syndrome ubiquitin ligase localizes to the synapse and nucleus, and maternal deficiency results in abnormal dendritic spine morphology. Hum Mol Genet 17: 111-118. doi:10.1093/hmg/ddm288

Dutta R, Crawley JN. 2019. Behavioral evaluation of Angelman syndrome mice at older ages. Neuroscience pii: S0306-4522(19)30719-5. doi:10 .1016/j.neuroscience.2019.10.027

Egawa K, Kitagawa K, Inoue K, Takayama M, Takayama C, Saitoh S, Kishino T, Kitagawa M, Fukuda A. 2012. Decreased tonic inhibition in cerebellar granule cells causes motor dysfunction in a mouse model of Angelman syndrome. Sci Transl Med 4: 163ra157. doi:10.1126/ scitranslmed.3004655

García-Díaz Barriga G, Giralt A, Anglada-Huguet M, Gaja-Capdevila N, Orlandi JG, Soriano J, Canals JM, Alberch J. 2017. 7,8-dihydroxyflavone ameliorates cognitive and motor deficits in a Huntington's disease mouse model through specific activation of the PLC $\gamma 1$ pathway. Hum Mol Genet 26: 3144-3160. doi:10.1093/hmg/ddx198

Giacomini A, Stagni F, Emili M, Uguagliati B, Rimondini R, Bartesaghi R, Guidi S. 2019. Timing of treatment with the flavonoid 7,8-DHF critically impacts on its effects on learning and memory in the Ts65Dn mouse. Antioxidants 8: E163. doi:10.3390/antiox8060163

Godavarthi SK, Sharma A, Jana NR. 2014. Reversal of reduced parvalbumin neurons in hippocampus and amygdala of Angelman syndrome model mice by chronic treatment of fluoxetine. J Neurochem 130: 444-454. doi:10.1111/jnc. 12726

Grier MD, Carson RP, Lagrange AH. 2015. Of mothers and myelin: aberrant myelination phenotypes in mouse model of Angelman syndrome are dependent on maternal and dietary influences. Behav Brain Res 291: 260-267. doi:10.1016/j.bbr.2015.05.045 
Guzzetti S, Calzari L, Buccarello L, Cesari V, Toschi I, Cattaldo S, Mauro A, Pregnolato F, Mazzola SM, Russo S. 2018. Taurine administration recovers motor and learning deficits in an Angelman syndrome mouse model. Int J Mol Sci 19: E1088. doi:10.3390/ijms19041088

Harting I, Seitz A, Rating D, Sartor K, Zschocke J, Janssen B, Ebinger F, Wolf NI. 2009. Abnormal myelination in Angelman syndrome. Eur J Paediatr Neurol 13: 271-276. doi:10.1016/j.ejpn.2008.04.005

Heck DH, Zhao Y, Roy S, LeDoux MS, Reiter LT. 2008. Analysis of cerebellar function in Ube3a-deficient mice reveals novel genotype-specific behaviors. Hum Mol Genet 17: 2181-2189. doi:10.1093/hmg/ddn117

Huang HS, Allen JA, Mabb AM, King IF, Miriyala J, Taylor-Blake B, Sciaky N, Dutton JW Jr, Lee HM, Chen X, et al. 2011. Topoisomerase inhibitors unsilence the dormant allele of Ube3a in neurons. Nature 481: 185-189. doi:10.1038/nature10726

Huang H-S, Burns AJ, Nonneman RJ, Baker LK, Riddick NV, Nikolova VD, Riday TT, Yashiro K, Philpot BD, Moy SS. 2013. Behavioral deficits in an Angelman syndrome model: effects of genetic background and age. Behav Brain Res 243: 79-90. doi:10.1016/j.bbr.2012.12.052

Jamal I, Kumar V, Vatsa N, Shekhar S, Singh BK, Sharma A, Jana NR. 2017. Rescue of altered HDAC activity recovers behavioural abnormalities in a mouse model of Angelman syndrome. Neurobiol Dis 105: 99-108. doi:10 .1016/j.nbd.2017.05.010

Jana NR. 2012. Understanding the pathogenesis of Angelman syndrome through animal models. Neural Plast 2012: 710943. doi:10.1155/2012/ 710943

Jiang Y, Lev-Lehman E, Bressler J, Tsai TF, Beaudet AL. 1999. Genetics of Angelman syndrome. Am J Hum Genet 65: 1-6. doi:10.1086/302473

Jiang YH, Pan Y, Zhu L, Landa L, Yoo J, Spencer C, Lorenzo I, Brilliant M, Noebels J, Beaudet AL. 2010. Altered ultrasonic vocalization and impaired learning and memory in Angelman syndrome mouse model with a large maternal deletion from Ube3a to Gabrb3. PLoS ONE 5: e12278. doi:10.1371/journal.pone.0012278

Jiang M, Peng Q, Liu X, Jin J, Hou Z, Zhang J, Mori S, Ross CA, Ye K, Duan W. 2013. Small-molecule TrkB receptor agonists improve motor function and extend survival in a mouse model of Huntington's disease. Hum Mol Genet 22: 2462-2470. doi:10.1093/hmg/ddt098

Johnson RA, Lam M, Punzo AM, Li H, Lin BR, Ye K, Mitchell GS, Chang Q. 1985. 7,8-dihydroxyflavone exhibits therapeutic efficacy in a mouse model of Rett syndrome. J Appl Physiol 112: 704-710. doi:10.1152/ japplphysiol.01361.2011

Kang M-S, Choi T-Y, Ryu HG, Lee D, Lee SH, Choi S-Y, Kim K-T. 2017. Autism-like behavior caused by deletion of vaccinia-related kinase 3 is improved by TrkB stimulation. J Exp Med 214: 2947-2966. doi:10.1084/ jem.20160974

Kaphzan H, Hernandez P, Jung JI, Cowansage KK, Deinhardt K, Chao MV, Abel T, Klann E. 2012. Reversal of impaired hippocampal long-term potentiation and contextual fear memory deficits in Angelman syndrome model mice by ErbB inhibitors. Biol Psychiatry 72: 182-190. doi:10.1016/j.biopsych.2012.01.021

Kazdoba TM, Hagerman RJ, Zolkowska D, Rogawski MA, Crawley JN. 2016. Evaluation of the neurosteroid ganaxolone on social and repetitive behaviors in the BTBR mouse model of autism. Psychopharmacology 233: 309-323. doi:10.1007/s00213-015-4115-7

Khatri N, Man H-Y. 2019. The autism and Angelman syndrome protein Ube3A/E6AP: the gene, E3 ligase ubiquitination targets and neurobiological functions. Front Mol Neurosci 12: 109. doi:10.3389/ fnmol.2019.00109

Khatri N, Gilbert JP, Huo Y, Sharaflari R, Nee M, Qiao H, Man H-Y. 2018. The autism protein Ube3A/E6AP remodels neuronal dendritic arborization via caspase-dependent microtubule destabilization. J Neurosci 38: 363378. doi:10.1523/JNEUROSCI.1511-17.2017

Kim H, Kunz PA, Mooney R, Philpot BD, Smith SL. 2016. Maternal loss of Ube3a impairs experience-driven dendritic spine maintenance in the developing visual cortex. J Neurosci 36: 4888-4894. doi:10.1523/ JNEUROSCI.4204-15.2016

Knoll JH, Nicholls RD, Magenis RE, Graham JM, Lalande M, Latt SA. 1989. Angelman and Prader-Willi syndromes share a common chromosome 15 deletion but differ in parental origin of the deletion. Am J Med Genet 32: 285-290. doi:10.1002/ajmg.1320320235

Kron M, Lang M, Adams IT, Sceniak M, Longo F, Katz DM. 2014. A BDNF loop-domain mimetic acutely reverses spontaneous apneas and respiratory abnormalities during behavioral arousal in a mouse model of Rett syndrome. Dis Model Mech 7: 1047-1055. doi:10.1242/dmm .016030

Larson AM, Shinnick JE, Shaaya EA, Thiele EA, Thibert RL. 2015. Angelman syndrome in adulthood. Am J Med Genet A 167: 331-344. doi:10.1002/ ajmg.a.36864

Lauterborn JC, Schultz MN, Le A, Amani M, Friedman AE, Leach PT, Gall CM, Lynch GS. 2019. Spaced training improves learning in Ts65Dn and Ube $3 a$ mouse models of intellectual disabilities. Transl Psychiatry 9: 166. doi:10.1038/s41398-019-0495-5
Leach PT, Crawley JN. 2018. Touchscreen learning deficits in Ube3a, Ts65Dn and Mecp2 mouse models of neurodevelopmental disorders with intellectual disabilities. Genes Brain Behav 17: e12452. doi:10.1111/gbb .12452

Leach PT, Hayes J, Pride M, Silverman JL, Crawley JN. 2016. Normal performance of Fmr1 mice on a touchscreen delayed nonmatching to position working memory task. eNeuro 3: e0143-15. doi:10.1523/ ENEURO.0143-15.2016

Leal G, Afonso PM, Salazar IL, Duarte CB. 2015. Regulation of hippocampal synaptic plasticity by BDNF. Brain Res 1621: $82-101$. doi:10.1016/j .brainres.2014.10.019

Lee PC, Dodart J-C, Aron L, Finley LW, Bronson RT, Haigis MC, Yankner BA, Harper JW. 2013. Altered social behavior and neuronal development in mice lacking the Uba6-Use1 ubiquitin transfer system. Mol Cell 50: 172184. doi:10.1016/j.molcel.2013.02.014

Lee H-M, Clark EP, Kuijer MB, Cushman M, Pommier Y, Philpot BD. 2018. Characterization and structure-activity relationships of indenoisoquinoline-derived topoisomerase I inhibitors in unsilencing the dormant Ube3a gene associated with Angelman syndrome. Mol Autism 9: 45. doi:10.1186/s13229-018-0228-2

Li W, Bellot-Saez A, Phillips ML, Yang T, Longo FM, Pozzo-Miller L. 2017. A small-molecule TrkB ligand restores hippocampal synaptic plasticity and object location memory in Rett syndrome mice. Dis Model Mech 10: 837-845. doi:10.1242/dmm.029959

Lin P-Y, Kavalali ET, Monteggia LM. 2018. Genetic dissection of presynaptic and postsynaptic BDNF-TrkB signaling in synaptic efficacy of CA3-CA1 synapses. Cell Rep 24: 1550-1561. doi:10.1016/j.celrep.2018.07.020

Liu Y, Johe K, Sun J, Hao X, Wang Y, Bi X, Baudry M. 2019. Enhancement of synaptic plasticity and reversal of impairments in motor and cognitive functions in a mouse model of Angelman Syndrome by a small neurogenic molecule, NSI-189. Neuropharmacology 144: 337-344. doi:10 .1016/j.neuropharm.2018.10.038

Llewellyn KJ, Nalbandian A, Gomez A, Wei D, Walker N, Kimonis VE. 2015. Administration of CoQ10 analogue ameliorates dysfunction of the mitochondrial respiratory chain in a mouse model of Angelman syndrome. Neurobiol Dis 76: 77-86. doi:10.1016/j.nbd.2015.01.005

Lynch G, Rex CS, Chen LY, Gall CM. 2008. The substrates of memory: defects, treatments, and enhancement. Eur J Pharmacol 585: 2-13. doi:10.1016/j.ejphar.2007.11.082

Mabb AM, Ehlers MD. 2010. Ubiquitination in postsynaptic function and plasticity. Annu Rev Cell Dev Biol 26: 179-210. doi:10.1146/ annurev-cellbio-100109-104129

Mabb AM, Judson MC, Zylka MJ, Philpot BD. 2011. Angelman syndrome: insights into genomic imprinting and neurodevelopmental phenotypes. Trends Neurosci 34: 293-303. doi:10.1016/j.tins.2011.04 .001

Mabb AM, Simon JM, King IF, Lee H-M, An L-K, Philpot BD, Zylka MJ. 2016. Topoisomerase 1 regulates gene expression in neurons through cleavage complex-dependent and -independent mechanisms. PLOS ONE 11: e0156439. doi:10.1371/journal.pone.0156439

Mandel-Brehm C, Salogiannis J, Dhamne SC, Rotenberg A, Greenberg ME. 2015. Seizure-like activity in a juvenile Angelman syndrome mouse model is attenuated by reducing Arc expression. Proc Natl Acad Sci 112: 5129-5134. doi:10.1073/pnas.1504809112

Margolis SS, Sell GL, Zbinden MA, Bird LM. 2015. Angelman syndrome. Neurotherapeutics 12: 641-650. doi:10.1007/s13311-015-0361-y

Meng L, Person RE, Beaudet AL. 2012. Ube3a-ATS is an atypical RNA polymerase II transcript that represses the paternal expression of Ube3a. Hum Mol Genet 21: 3001-3012. doi:10.1093/hmg/dds130

Meng L, Ward AJ, Chun S, Bennett CF, Beaudet AL, Rigo F. 2015. Towards a therapy for Angelman syndrome by targeting a long non-coding RNA. Nature 518: 409-412. doi:10.1038/nature 13975

Miura K, Kishino T, Li E, Webber H, Dikkes P, Holmes GL, Wagstaff J. 2002. Neurobehavioral and electroencephalographic abnormalities in Ube3a maternal-deficient mice. Neurobiol Dis 9: 149-159. doi:10.1006/nbdi .2001 .0463

Monteggia LM. 2011. Toward neurotrophin-based therapeutics. Am J Psychiatry 168: 114-116. doi:10.1176/appi.ajp.2010.10111677

Nasrallah P, Haidar EA, Stephan JS, El Hayek L, Karnib N, Khalifeh M, Barmo N, Jabre V, Houbeika R, Ghanem A, et al. 2019. Branched-chain amino acids mediate resilience to chronic social defeat stress by activating BDNF/TRKB signaling. Neurobiol Stress 11: 100170. doi:10 .1016/j.ynstr.2019.100170

Nguyen HTH, Wood RJ, Prawdiuk AR, Furness SGB, Xiao J, Murray SS, Fletcher JL. 2019. TrkB agonist LM22A-4 increases oligodendroglial populations during myelin repair in the corpus callosum. Front Mol Neurosci 12: 205. doi:10.3389/fnmol.2019.00205

Nicholls RD. 1993. Genomic imprinting and uniparental disomy in Angelman and Prader-Willi syndromes: a review. Am J Med Genet 46: 16-25. doi:10.1002/ajmg.1320460106 
Park H, Poo MM. 2013. Neurotrophin regulation of neural circuit development and function. Nature Rev Neurosci 14: 7-23. doi:10.1038/ nrn3379

Peters SU, Kaufmann WE, Bacino CA, Anderson AW, Adapa P, Chu Z, Yallampalli R, Traipe E, Hunter JV, Wilde EA. 2011. Alterations in white matter pathways in Angelman syndrome. Dev Med Child Neurol 53: 361-367. doi:10.1111/j.1469-8749.2010.03838.x

Powell WT, Coulson RL, Gonzales ML, Crary FK, Wong SS, Adams S, Ach RA, Tsang P, Yamada NA, Yasui DH, et al. 2013. R-loop formation at Snord116 mediates topotecan inhibition of Ube3a-antisense and allele-specific chromatin decondensation. Proc Natl Acad Sci 110: 13938-13943. doi:10.1073/pnas.1305426110

Prasad A, Grocott O, Parkin K, Larson A, Thibert RL. 2018. Angelman syndrome in adolescence and adulthood: a retrospective chart review of 53 cases. Am J Med Genet A 176: 1327-1334. doi:10.1002/ajmg.a.38694

Rayi PR, Koyavski L, Chakraborty D, Bagrov A, Kaphzan H. 2019. $\alpha 1-\mathrm{Na}$ / K-ATPase inhibition rescues aberrant dendritic calcium dynamics and memory deficits in the hippocampus of an Angelman syndrome mouse model. Prog Neurobiol 182: 101676. doi:10.1016/j.pneurobio.2019 .101676

Reichardt LF. 2006. Neurotrophin-regulated signalling pathways. Philos Trans R Soc Lond B Biol Sci 361: 1545-1564. doi:10.1098/rstb.2006.1894

Ren Q, Zhang J-C, Ma M, Fujita Y, Wu J, Hashimoto J. 2014. 7,8-Dihydroxyflavone, a TrkB agonist, attenuates behavioral abnormalities and neurotoxicity in mice after administration of methamphetamine. Psychopharmacology 231: 159-166. doi:10.1007/ s00213-013-3221-7

Rhine MA, Parrott JM, Schultz MN, Kazdoba TM, Crawley JN. 2019. Hypothesis-driven investigations of diverse pharmacological targets in two mouse models of autism. Autism Res 12: 401-421. doi:10.1002/aur .2066

Rotaru DC, van Woerden GM, Wallaard I, Elgersma Y. 2018. Adult Ube3a gene reinstatement restores the electrophysiological deficits of prefrontal cortex layer 5 neurons in a mouse model of Angelman syndrome. J Neuroscience 38: 8011-8030. doi:10.1523/JNEUROSCI .0083-18.2018

Santini E, Turner KL, Ramaraj AB, Murphy MP, Klann E, Kaphzan H. 2015. Mitochondrial superoxide contributes to hippocampal synaptic dysfunction and memory deficits in Angelman syndrome model mice. $J$ Neuroscience 35: 16213-16220. doi:10.1523/JNEUROSCI.2246-15.2015

Schuman EM. 1999. Neurotrophin regulation of synaptic transmission. Curr Opin Neurobiol 9: 105-109. doi:10.1016/S0959-4388(99)80013-0

Sconce MD, Churchill MJ, Moore C, Meshul CK. 2015. Intervention with 7,8-dihydroxyflavone blocks further striatal terminal loss and restores motor deficits in a progressive mouse model of Parkinson's disease. Neuroscience 290: 454-471. doi:10.1016/j.neuroscience.2014.12.080

Seese RR, Le AA, Wang K, Cox CD, Lynch G, Gall CM. 2020. A TrkB agonist and ampakine rescue synaptic plasticity and multiple forms of memory in a mouse model of intellectual disability. Neurobiol Dis 134: 104604. doi:10.1016/j.nbd.2019.104604

Silva-Santos S, van Woerden GM, Bruinsma CF, Mientjes E, Jolfaei MA, Distel B, Kushner SA, Elgersma Y. 2015. Ube3a reinstatement identifies distinct developmental windows in a murine Angelman syndrome model. J Clin Invest 125: 2069-2076. doi:10.1172/JCI80554

Silverman JL, Turner SM, Barkan CL, Tolu SS, Saxena R, Hung AY, Sheng M, Crawley JN. 2011. Sociability and motor functions in Shank1 mutant mice. Brain Res 1380: 120-137. doi:10.1016/j.brainres.2010.09.026

Silverman JL, Smith DG, Sukoff Rizzo SJ, Karras MN, Turner SM, Tolu SS, Bryce DK, Smith DL, Fonseca K, Ring RH, et al. 2012. Negative allosteric modulation of the mGluR5 receptor reduces repetitive behaviors and rescues social deficits in mouse models of autism. Science Transl Med 4: 131ra51. doi:10.1126/scitranslmed.3003501

Simmons DA, Belichenko NP, Yang T, Condon C, Monbureau M, Shamloo M, Jing D, Massa SM, Longo FM. 2013. A small molecule TrkB ligand reduces motor impairment and neuropathology in R6/2 and BACHD mouse models of Huntington's disease. J Neurosci 33: 1871218727. doi:10.1523/JNEUROSCI.1310-13.2013

Smith JC. 2001. Angelman syndrome: evolution of the phenotype in adolescents and adults. Dev Med Child Neurol 43: 476-480. doi:10.1017/ S0012162201000871
Sonzogni M, Wallaard I, Santos SS, Kingma J, du Mee D, van Woerden GM, Elgersma Y. 2018. A behavioral test battery for mouse models of Angelman syndrome: a powerful tool for testing drugs and novel Ube3a mutants. Mol Autism 9: 47. doi:10.1186/s13229-018-0231-7

Sonzogni M, Hakonen J, Bernabé Kleijn M, Silva-Santos S, Judson MC, Philpot BD, van Woerden GM, Elgersma Y. 2019. Delayed loss of UBE3A reduces the expression of Angelman syndrome-associated phenotypes. Mol Autism 10: 23. doi:10.1186/s13229-019-0277-1

Stagni F, Giacomini A, Guidi S, Emili M, Uguagliati B, Salvalai ME, Bortolotto V, Grilli M, Rimondini R, Bartesaghi R. 2017. A flavonoid agonist of the TrkB receptor for BDNF improves hippocampal neurogenesis and hippocampus-dependent memory in the Ts65Dn mouse model of DS. Exp Neurol 298: 79-96. doi:10.1016/j.expneurol .2017.08.018

Stoppel DC, Anderson MP. 2017. Hypersociability in the Angelman syndrome mouse model. Exp Neurol 293: 137-143. doi:10.1016/j .expneurol.2017.04.002

Stoppel LJ, Kazdoba TM, Schaffler MD, Preza AR, Heynen A, Crawley JN, Bear MF. 2018. R-baclofen reverses cognitive deficits and improves social interactions. Neuropsychopharmacology 43: 513-524. doi:10.1038/npp .2017 .236

Sun J, Liu Y, Moreno S, Baudry M, Bi X. 2015. Imbalanced mechanistic target of rapamycin C1 and C2 activity in the cerebellum of Angelman syndrome mice impairs motor function. J Neurosci 35: 4706-4718. doi:10.1523/JNEUROSCI.4276-14.2015

Sun J, Liu Y, Tran J, O’Neal P, Baudry M, Bi X. 2016. mTORC1-S6K1 inhibition or mTORC2 activation improves hippocampal synaptic plasticity and learning in Angelman syndrome mice. Cell Mol Life Sci 73: 4303-4314. doi:10.1007/s00018-016-2269-z

Tan WH, Bird LM. 2016. Angelman syndrome: current and emerging therapies in 2016. Am J Med Genet C Semin Med Genet 172: 384-401. doi:10.1002/ajmg.c.31536

Thoenen H. 1995. Neurotrophins and neuronal plasticity. Science 270: 593598. doi:10.1126/science.270.5236.593

Tian M, Zeng Y, Hu Y, Yuan X, Liu S, Li J, Lu P, Sun Y, Gao L, Fu D, et al. 2015. 7, 8-Dihydroxyflavone induces synapse expression of AMPA GluA1 and ameliorates cognitive and spine abnormalities in a mouse model of fragile X syndrome. Neuropharmacology 89: 43-53. doi:10.1016/j .neuropharm.2014.09.006

Tiwari VN, Jeong J-W, Wilson BJ, Behen ME, Chugani HT, Sundaram SK. 2012. Relationship between aberrant brain connectivity and clinical features in Angelman syndrome: a new method using tract based spatial statistics of DTI color-coded orientation maps. Neuroimage 59: 349-355. doi:10.1016/j.neuroimage.2011.07.067

van Woerden GM, Harris KD, Hojjati MR, Gustin RM, Qiu S, de Avila Freire R, Jiang YH, Elgersma Y, Weeber EJ. 2007. Rescue of neurological deficits in a mouse model for Angelman syndrome by reduction of $\alpha$ CaMKII inhibitory phosphorylation. Nat Neurosci 10: 280-282. doi:10 $.1038 / \mathrm{nn} 1845$

Vatsa N, Kumar V, Singh BK, Kumar SS, Sharma A, Jana NR. 2019. Down-regulation of miRNA-708 promotes aberrant calcium signaling by targeting neuronatin in a mouse model of Angelman syndrome. Front Mol Neurosci 12: 35. doi:10.3389/fnmol.2019.00035

Wheeler AC, Sacco P, Cabo R. 2017. Unmet clinical needs and burden in Angelman syndrome: a review of the literature. Orphanet J Rare Dis 12: 164. doi:10.1186/s13023-017-0716-z

Williams C, Franco L. 2010. Angelman syndrome at the synapse: meeting report of the Angelman Syndrome Foundation's 2009 scientific symposium. J Child Neurol 25: 254-261. doi:10.1177/ 0883073809353450

Williams CA, Driscoll DJ, Dagli AI. 2010. Clinical and genetic aspects of Angelman syndrome. Genet Med 12: 385-395. doi:10.1097/GIM Ob013e3181def138

Zylka MJ. 2020. Prenatal treatment path for Angelman syndrome and other neurodevelopmental disorders. Autism Res 13: 11-17. doi:10 .1002/aur.2203

Received November 19, 2019; accepted in revised form February 11, 2020. 


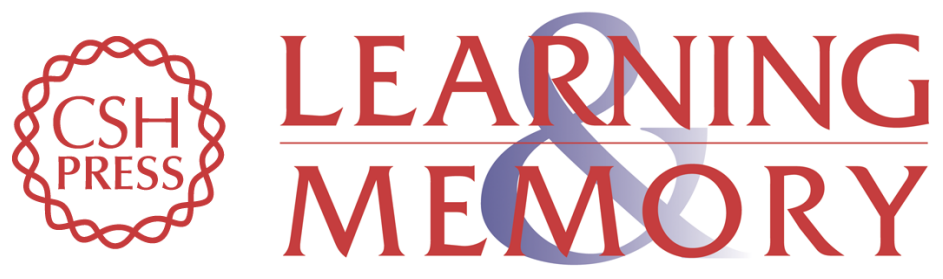

\section{Evaluation of a TrkB agonist on spatial and motor learning in the Ube3a mouse model of Angelman syndrome}

Maria N. Schultz and Jacqueline N. Crawley

Learn. Mem. 2020, 27:

Access the most recent version at doi:10.1101//m.051201.119

\section{Supplemental http://learnmem.cshlp.org/content/suppl/2020/08/13/27.9.346.DC1 Material}

References This article cites 104 articles, 15 of which can be accessed free at: http://learnmem.cshlp.org/content/27/9/346.full.html\#ref-list-1

Creative This article, published in Learning \& Memory, is available under a Creative Commons Commons License (Attribution-NonCommercial 4.0 International), as described at License http://creativecommons.org/licenses/by-nc/4.0/.

Email Alerting Receive free email alerts when new articles cite this article - sign up in the box at the Service top right corner of the article or click here. 